\title{
Oficina de cirurgia cutânea
}

\section{Cutaneous surgery workshop}

Kátia Sheylla Malta Purim¹

\author{
RE S U M O
}

\begin{abstract}
A formação profissional do médico demanda a aquisição de conhecimentos, habilidades e atitudes para o bom exercício da prática profissional. O treinamento de técnicas cirúrgicas básicas, usadas na cirurgia ambulatorial, irá prepará-lo para atuar em diferentes cenários. Apresentamos proposta de ensino através de oficina de cirurgia cutânea em modelo experimental.
\end{abstract}

Descritores: Educação médica. Procedimentos cirúrgicos ambulatoriais. Ensino.

\section{O ENSINO DE CIRURGIA CUTÂNEA DURANTE A GRADUAÇÃO}

A diretrizes curriculares apontam que é fundamental ao médico ter uma sólida formação básica e geral, treinamento em todos os níveis de atenção a saúde (primário, secundário e terciário), elevada formação ética e humanista, responsabilidade social e que, ao ser lançado no mercado, apresente competência técnica para exercer a profissão.

No período da graduação, o acadêmico é estimulado a participar de atividades teóricas e práticas para enriquecer sua formação. Nas disciplinas cirúrgicas são utilizadas diversas estratégias pedagógicas para atingir este objetivo. Porém, o limitado tempo para conciliar a teoria e prática, as dificuldades de recursos humanos e materiais, nem sempre permitem um adequado domínio das técnicas.

Os alunos tendem a buscar atividades extracurriculares para suprir suas carências, curiosidades ou desejo de maior treinamento de habilidades específicas, seja em estágios, plantões de pronto-socorro, acompanhamento de cirurgiões, serviços hospitalares, ambulatórios de procedimentos e projetos de complementação do ensino ${ }^{1,2}$.

Dentre os modelos experimentais empregados na medicina, e que sejam eticamente aceitos, a pata de porco pode ser utilizada no desenvolvimento de competências para tratamento de diversas lesões que afetam a pele. Estas operações incluem manejos simples como biópsias, remoção de nevos, cistos, lipomas, tumores benignos e outras, além de técnicas especializadas para a terapia do câncer cutâneo usando retalhos e enxertos.
Para ampliar o treinamento prático supervisionado durante a graduação, foi montada uma proposta dinâmica de ensino de cirurgia cutânea, em forma de oficina, como parte de um plano de inovação pedagógica.

\section{Montando uma Oficina com pata de porco}

Esta oficina deve ser discutida com a Coordenação do Curso de Medicina, elaborada como projeto de extensão e submetida ao Comitê de Ética em Pesquisa. As normas para o treinamento devem seguir as diretrizes curriculares, a legislação sanitária e demais resoluções vigentes.

O público-alvo são os acadêmicos do terceiro e/ ou quarto ano de medicina que optem em complementar seu treinamento cirúrgico. Para maior aproveitamento, recomenda-se como pré-requisito mínimo que já tenham cursado a disciplina de técnica operatória ou equivalente.

Estes acadêmicos precisam receber previamente orientações detalhadas sobre os procedimentos cirúrgicos e um roteiro com os exercícios práticos. Serão monitorados através da supervisão direta de professores e auxiliares durante a realização das técnicas operatórias, com o objetivo de incorporar os conhecimentos expressos nas aprendizagens.

Os auxiliares da oficina podem ser médicos residentes ou alunos que já tenham se submetido a treinamentos anteriores. Para otimizar o andamento das práticas, este grupo também precisa ser esclarecido das finalidades da oficina e demonstrar habilidades básicas para cirurgia. Calcula-se que seis professores, seis residentes e seis alunos, todos capacitados, sejam suficientes para atender 60 acadêmicos. As atividades desta monitoria estão listadas na tabela 1.

Projeto realizado no Curso de Medicina da Universidade Positivo - Curitiba - PR-BR.

1. Médica Dermatologista; Doutora em Medicina e Ciências da Saúde (UFPR) - Curitiba - PR-BR. Professora das Disciplinas de Dermatologia e Cirurgia Ambulatorial do Curso de Medicina da Universidade Positivo (UP) - Curitiba - PR-BR. 


\section{ATIVIDADE DE MONITORIA}

Devem ser realizadas reuniões de planejamento com a equipe e entre os tópicos discutir como maximizar os resultados deste projeto. Além do pessoal de apoio devidamente treinado e motivado, são necessários recursos multimídia (computador, datashow e telão), suporte financeiro e estrutura física apropriada. O planejamento inclui providenciar em quantidade suficiente para o número de acadêmicos inscritos: 1. Roteiro com desenhos e esquemas dos exercícios cirúrgicos; canetas marcadoras de pele; fios de sutura agulhados; material cirúrgico fixo (kit cirúrgico individual): tesoura, pinça anatômica, pinça dente de rato ou gancho, porta agulha e cabo de bisturi ; luvas cirúrgicas ; lâminas de bisturi número 15; patas de porco resfriadas ou descongeladas; container para descarte de material pérfuro-cortante.

No dia agendado, os alunos são recepcionados pelos professores, auxiliares e monitores em uma sala de aula para orientações gerais, entrega do material cirúrgico e mini-apostila com roteiro dos exercícios práticos: uso de punch, curetagem, biópsias, tipos de incisões, excisões, movimentos dos tecidos, retalhos, noções de enxertos e suturas 3 . O programa básico do treinamento está registrado na tabela 2.

Após identificação, colocação de jaleco e conferência do material, os estudantes são encaminhados ao centro cirúrgico experimental e distribuídos em dez mesas cirúrgicas. Formam-se grupos de seis pessoas para realização das atividades com a presença de um monitor por mesa. Cada exercício é precedido de explicação prévia por um dos professores e demonstração em multimídia. O método repetitivo-comparativo é utilizado para permitir que o aluno compreenda concretamente o passo a passo para a realização de cada tarefa ${ }^{1,2}$.

A duração prevista da oficina é de quatro horas, incluindo uma auto-avaliação dos estudantes contraposta a avaliação dos professores, segundo critérios preestabelecidos, e registro do aprendizado a partir de questionários. O acadêmico é estimulado a discutir suas dúvidas com o grupo de indivíduos da sua mesa e apresentar ao supervisor seu conhecimento prático, reproduzindo na pata de porco e/ou explicando as técnicas demonstradas.

A principal limitação deste treinamento é que o ato operatório é restrito as condições do modelo desvitalizado. Diferentemente da cirurgia ao vivo, o pro-

Tabela 1 - Atividades dos monitores e auxiliares da oficina de ensino de cirurgia cutânea.

1. estudar e dominar a sequência de exercícios da oficina

2. estar presente pontualmente 30 minutos antes do horário agendado

3. levar mini-apostila com o roteiro dos exercícios

4. usar jaleco branco, calçado fechado e roupa confortável recepcionar e encaminhar os alunos inscritos auxiliar na distribuição do material para o seu grupo conferir entrega do kit cirúrgico, fios e lamina de bisturi seguir o esquema proposto na mini-apostila

5. auxiliar os alunos na execução dos exercícios práticos manter a ordem na mesa cirúrgica zelar pelo uso do material permanente e de consumo

6. supervisionar o descarte de resíduos perfuro-cortantes

7. conferir devolução completa do kit cirúrgico no final do curso

8. colaborar com a higiene e organização do local

Tabela 2 - Programa de treinamento em pata de porco.

1. biópsia por punch e curetagem

2. fuso, descolamento, sutura subcutânea e simples

3. outras suturas ( $U$ vertical = Donati, contínua e intradérmica)

4. correção de orelhas e plastia em " $M$ "

5. retalho de transposição e zetaplastia

6. técnica de avanço " $\mathrm{VY}$ "

7. retalho de avanço simples e duplo

8. retalho de rotação simples e duplo

9. enxerto de pele total. 
cesso exclui instrumentação, paramentação, anestesia, hemostasia, reação do tecido ao trauma, eventuais complicações cirúrgicas, atuação hierárquica na equipe e relação médico-paciente 4 .

O tecido congelado é mais endurecido e requer estrutura, espaço e condições adequadas para armazenamento. O tempo e processo de descongelamento das patas de porco podem dificultar a técnica operatória e gerar perda de fios agulhados. O risco de acidente perfuro-cortante está presente e se relaciona ao manuseio de agulhas, lâminas de bisturi e tesouras.

Esta proposta pedagógica reduz custos para a instituição pela dispensa de fornecimento de uniforme cirúrgico, anestésico e outros gastos. Como as patas são provenientes de animal utilizado em aulas prévias de cirurgia, há um melhor aproveitamento do modelo experimental existente.

Os professores circulam em todas as mesas para conferir o desempenho nas técnicas cirúrgicas e realizar correções quando necessárias. Isto possibilita uma relação ensino-aprendizagem mais efetiva, pelo compromisso com o exercício proposto, as idéias apresentadas e o retorno recebido. Observam-se melhor as dificuldades individuais e coletivas, bem como, as tendências de treinamento de habilidades operatórias mais procuradas 5 .

Todos os estudantes são treinados simultaneamente em um ambiente favorável ao aprendizado. Neste cenário colaborativo são desafiados, de forma equilibrada e interativa, a utilizar conhecimentos e habilidades prévias, e estimulados a avançar na exploração, pesquisa e solução dos problemas propostos para corrigir defeitos cirúrgicos ${ }^{6}$.

Este modelo de ensino possibilita a construção do conhecimento e o desenvolvimento de técnicas comumente usadas na prática cirúrgica ambulatorial de diversas especialidades. Ao final da oficina o acadêmico deverá se sentir mais preparado para os procedimentos envolvendo o sistema tegumentar e ser capaz de realizar cirurgias ambulatoriais de pequeno porte do dia a dia médico ${ }^{7}$.

\section{A B S S T R A C T}

The training of physician request knowledge, skills and attitudes for the effective exercise of professional practice. The training of basic surgical techniques, used in outpatient procedures, will prepare students to work in different scenarios. This work presents a proposal for teaching through workshops for cutaneous surgery in an experimental model.

Key words: Education. Medical. Ambulatory surgical procedures. Teaching.

\section{REFERÊNCIAS}

1. Arenson-Pandikow HM. Estágio em urgência e emergência: projeto integrado de avaliação do ensino médico. Rev Bras Educ Med. 1994; 18(3):116-20.

2. Gib MC, Bellini LP, Pimentel M, Almeida HC. Projeto de complementação do ensino médico em cirurgias ambulatoriais. Rev Bras Educ Med. 2001; 25(3):64-7

3. Gontijo GT, Furtado T, Salgado JA. A dermatologia no ensino ambulatorial de cirurgia. An Bras Dermatol. 1992; 67(1):21-6.

4. Jesus LE. Ensinar cirurgia: como e para quem? Rev Col Bras Cir. 2008; 35(2):136-40

5. Kope LF, Tatsuo ES, Drumond DAF, Andrade JS, Tostes ROG, Costa SM et. A formação do cirurgião dermatológico. An Bras Dermatol. 1992; 67(4):141-3.

6. Neuhaus P. Why should young doctors choose to become surgeons? Ann Surg. 2007; 246(6):911-5.
7. Skinovsky J, Fernandes JW, Purim KSM. Cirurgia Ambulatorial. Rio de Janeiro: Revinter; 2009.

Recebido em 26/02/2010

Aceito para publicação em 02/04/2010

Conflito de interesse: nenhum

Fonte de financiamento: nenhuma

Como citar esse artigo:

Purim KSM. Oficina de cirurgia cutânea - ensino. Rev Col Bras Cir. [periódico na Internet] 2010; 37(4). Disponível em URL: http:// www.scielo.br/rcbc

Endereço para correspondência:

Kátia Sheylla Malta Purim

E-mail: katiasheylla@up.edu.br 